\title{
Survey Mil
}

National Cancer Institute

\section{Source}

National Cancer Institute. Survey Mil. NCI Thesaurus. Code C71224.

A unit of leng th equal to one thousandth of survey inch or 25.4000508001016002032004

microns. 